\title{
A mulher camponesa amazônica e a feira de produtos regionais: uma transformação no seu habitus
}

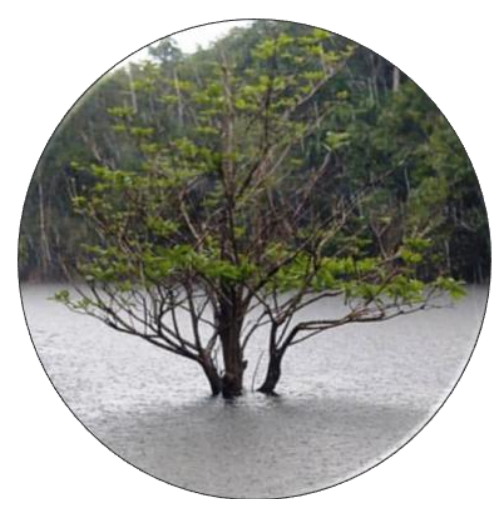

\author{
Rosane M. Brum V argas $^{1}$ \\ Therezinha J.Pinto Fraxe ${ }^{2}$ \\ Albejamere Pereira Castro ${ }^{3}$
}

\begin{abstract}
"Quando descobrimos que bá diversas culturas ao invés de apenas uma e consequentemente na hora em que reconhecemos o fim de um tipo de monopólio cultural, seja ele ilusório ou real, somos ameaçados com a destruição de nossa própria descoberta, subitamente torna-se possivel que só existam outros, que nós próprios somos um 'outro' entre outros. '...
\end{abstract}

Paul Ricoeur

"Civilizações e Culturas Nacionais", em seu História e Verdade.

\begin{abstract}
Resumo
As feiras de produtos regionais criadas pela ADS em Manaus, para uma política de desenvolvimento sustentável do Governo do Estado (ADS), vêm mudando a vida de algumas mulheres camponesas. Estas representam uma parcela significativa de contribuição no sustento familiar, exercendo uma pluriatividade no meio rural, a qual envolve a casa e o labor na agricultura. Embora, por questões culturais e políticas, os trabalhos realizados por essas mulheres sejam reconhecidos apenas como ajuda. A grande maioria das famílias camponesas no Amazonas ainda
\end{abstract}

1 Mestranda em Ciências Ambientais e Sustentabilidade da Amazônia (CCA/UFAM), Advogada (Direito Socioambiental), Licenciatura em Matemática e Bolsista CNPq. Email: rosanebv.adv@gmail.com.

2 Doutora em Sociologia Ambiental/UFC/CE.; Diretora do Centro de Ciências Ambientais/UFAM. Engenheira Agrônoma, Professora Titular do Departamento de Agronomia da UFAM/AM. Email: tecafraxe@uol.com.br.

3 Doutora em Agronomia Tropical; Pesquisadora do Núcleo de Socioeconomia (NUSEC/FCA/UFAM); Professora Titular da UFAM. Email: albejamere@ufam.edu.br 
é representada pelo sistema patriarcal. Quem administra a divisão do trabalho é o patriarca. O que essas mulheres camponesas buscam é um outro rumo, uma outra definição para a divisão do trabalho dentro da unidade produtiva, gerar uma renda extra, buscam uma certa autonomia. As feiras criaram um espaço onde o papel da mulher vem sofrendo alterações nas relações sociais e familiares, aumentando a renda e a dignidade, passando a ter reconhecimento.

Palavras-chaves: Mulher Camponesa, Feira Regional, Habitus, Amazonas.

\begin{abstract}
The regional product fairs created by ADS in Manaus for a sustainable development policy of the State Government (ADS) have been changing the lives of some peasant women. These represent a significant portion of the contribution to family support, exerting a plurality in the rural environment, which involves home and labor in agriculture. Although, for cultural and political reasons, the work done by these women is recognized only as an aid. The vast majority of peasant families in the Amazon are still represented by the patriarchal system. Whoever manages the division of labor is the patriarch. What these peasant women seek is another direction, another definition for the division of labor within the productive unit, generate extra income, seek a certain autonomy. The fairs have created a space where the role of women has been altered in social and family relations, increasing income and dignity, and now have recognition.
\end{abstract}

Keywords: Peasant Woman, Regional Fair, Habitus, Amazonas.

\title{
Introdução
}

Por vezes o papel da mulher é secundarizado na sociedade e na agricultura. Algumas mulheres tomam a decisão de se posicionar contra o modo atual de produção, na qual se afirma um modelo de sociedade que relega ao universo do campo a dependência, a monocultura e o empobrecimento. Estes modelos têm sido fatores de êxodo rural, em especial para os jovens e, às mulheres que tem seu papel inferiorizado na unidade produtiva sendo estimuladas para a migração, pois veem a cidade como um lugar de possibilidades de acesso a renda e autonomia, aos estudos, lazer, cultura, principalmente no estado do Amazonas, onde os povos ribeirinhos são atraídos pelo fetiche da Zona Franca de Manaus..

A mulher camponesa, de acordo com FRAXE (2011), vive em seu cotidiano uma jornada de trabalho intensa: ela é mãe, doméstica, agricultora, pescadora e extratora. Apesar de sua participação social e política na comunidade, na maioria das vezes, é diminuta em relação à participação dos homens. Existem 
inclusive comunidades em que as mulheres não podem fazer parte do conselho comunitário.

O fato de algumas comunidades não permitirem a presença das mulheres nas reuniões do conselho, pode ser explicado, pela noção de habitus, através de Bourdieu (1979):

O habitus seria o produto de todo esse longo trabalho de inculcação e apropriação que, mesmo que muito mais intenso e determinante durante as primeiras experiências do mundo social, prolonga-se por toda a existência dos agentes. Esse trabalho se faz necessário para que as estruturas objetivas consigam reproduzir-se, sob a forma de disposições "duráveis", em todos os organismos (individuais) duravelmente submetidos aos mesmos condicionamentos, colocados nas mesmas condições de existência. (1979: 73-75).

As estruturas de um habitus anterior comandam, portanto, o processo de estruturação de novos habitus a serem produzidos por novas agências pedagógicas. Conforme MICELI (1992) citado em FRAXE (2008), o habitus é um sistema de disposições do passado que sobrevive no atual, atualizando-se nas práticas, e tende a perpetuar-se, antecipando o porvir.

Nas unidades domésticas das famílias camponesas, na participação da mão de obra familiar, ainda está presente a divisão do trabalho por gênero: O Homem cuida da produção, da roça (capina, lavoura, pesca, extração, etc), e a mulher cuida das tarefas do lar (casa, filhos, preparar alimentos, galinhas, horta e demais tarefas do entorno da casa). Isto está socialmente posto e imposto e varia no tempo. A grande maioria das famílias camponesas no Amazonas ainda é representada pelo sistema patriarcal. Quem administra a divisão do trabalho é o patriarca. (Fraxe, 2011).

Mesmo a mulher camponesa, exercendo de forma intensa, múltiplas atividades no sistema agroflorestal, é a família como um todo, incluindo os agregados, a maior responsável pela execução das atividades planejadas e consequentemente pela produção. O que essas mulheres camponesas buscam é um outro rumo, uma outra definição para a divisão do trabalho dentro da unidade produtiva, gerar uma renda extra, buscam uma certa autonomia. 
A população rural do Amazonas, em sua maior parcela é constituída por ribeirinhos, ou seja, pelas chamadas populacõoes tradicionais que vivem em ecossistemas de várzea (rios, paranás, lagos, furos, igarapés, etc.) organizados em comunidades. As famílias ribeirinhas desenvolvem suas atividades nas terras, nas florestas e nas águas de trabalho, produzindo valores de uso para sua subsistência e valor de troca para a comercialização, tendo, como objetivo, a obtenção de renda que lhes permite comprar as mercadorias necessárias à sua reprodução social. Contudo, como indicam as pesquisas realizadas, é notória a situação de exclusão em que se encontram muitas famílias ribeirinhas. (Witikoski, 2008).

Nas colocações acima, WITKOSKI, conclui ainda, que entre os aspectos que contribuem para a configuração da situação de exclusão, destacam-se a falta de políticas de inclusão social - em suas dimensões econômicas, sociais, políticas e culturais - voltadas para a melhoria da sua qualidade de vida. (2006).

Nesse diapasão, frente às organizações comunitárias e cooperativas de agricultores é que o Governo do Amazonas, através da ADS (Agencia de Desenvolvimento Sustentável), numa política pública de inclusão social e sustentabilidade, implantou o projeto de feiras de comercialização produtos regionais, onde o camponês produz e vende diretamente ao consumidor o produto de seu trabalho, sem precisar se submeter aos agentes tradicionais de comercialização (marreteiro, regatão, patrão, etc.).

O projeto feiras de produtores regionais, fruto de parcerias da ADS com o Exército Brasileiro e Prefeituras diversas do interior do Amazonas, iniciou-se em 2008, com a Feira de Produtos Regionais do CIGS (Centro de Instrução de Guerra na Selva), mais tarde as Feiras da Cidade Nova, da Polícia Militar e por ultimo, em 2012 a feira do CASSAM (Cassino da Aeronáutica dos Subtenentes e Sargentos de Manaus) ou da Aeronáutica, denominada esta, de Feira da Economia Feminista e Solidária de Produtos Regionais. No decorrer dos últimos anos, após a feira do CIGS (2008) os organizadores perceberam o interesse e a grande participação de mulheres camponesas agricultoras, levandoos assim a criar a feira da CASSAM, uma feira especifica para estas mulheres. O 
estudo em questão centra-se nas mulheres camponesas feirantes que vendem seus produtos nas feiras do CIGS e CASSAM, por questões de delimitação de tempo e espaço e semelhanças com o local que abriga as feiras, entre outros.

As mulheres e famílias camponesas de Manaus e interior, iniciaram sua participação através dos sindicatos e comunidades locais, tendo em comum a busca pela dignidade da família, permanência no campo e autonomia feminina entre outros.

As feiras de produtores rurais, se tornaram espaços de (re)existência. O trabalho camponês se (re)forma através de seu "pensamento social agrário alternativo" (Gusmán e Molina, 2005) e vem se firmando através de atitudes que comprovam a sua resistência em versatilidade em produzir e resistir, lutando contra toda a forma de dominação e discriminação. È a reinvenção do habitus.

\section{A racionalidade econômica camponesa}

O camponês amazônico é a personificação da forma de produção simples de mercadorias. Segundo Fraxe (2011) nesse tipo de produção ele detém a propriedade da terra, da água e dos instrumentos de trabalho com os quais desenvolve suas atividades. Tavares (1984), afirma que essa combinação de elementos faz com que o camponês se apresente no mercado como vendedor dos produtos de seu trabalho e como produtor direto de mercadorias.

A produção camponesa realiza os ciclos mercadoria-mercadoria e mercadoria - dinheiro - mercadoria, os agentes articulam o mundo rural com o mundo urbano. Embora se verifique, aqui, a presença do dinheiro a troca se caracteriza, por uma economia mercantil de troca simples. De acordo com Marx, citado em Fraxe (2011) “a circulação simples de mercadoria (vender e comprar) serve de meio a um fim situado fora da circulação, a apropriação de valores de uso, a satisfação de necessidades”. (1968:171).

Nas comunidades camponesas, de acordo com Noda (2007), verifica-se de forma complementar e simultânea, a combinação de duas atividades 
econômicas: produção de meios de vida e a produção de mercadorias. Atividades essas operadas diretamente pela família, a unidade de produção é a família. Conforme Noda et al (1997), a predominância das hortaliças convencionais talvez seja a característica mais marcante dos atuais sistemas agrícolas de várzea, cerca de dez espécies, sendo que esta produção está voltada principalmente para o abastecimento dos mercados urbanos.

$\mathrm{Na}$ circulação e comercialização da produção camponesa, ocorre uma apropriação dos excedentes produzidos por um conjunto de "agentes de comercialização" marreteiro, marreteiro-feirante, regatão e patrão. Segundo Noda (2007), estes agentes são genericamente denominados de intermediários, e encontram-se em diferentes locais, sendo os principais nas beiras dos rios nas moradias dos produtores, os portos, as feiras e mercados e em constante movimento em suas embarcações fluviais. Nessa relação camponês-intermediário, está representado a subordinação do camponês à vontade do capital comercial. A inexistência de políticas agrícolas e agrária, voltadas ao campesinato na Amazônia, a produção de excedentes pelo sobretrabalho familiar em ambiente favorável e frugalidade na maneira de viver dos agricultores familiares, favorece o aparecimento desses agentes de comercialização. (FRAXE, 2011).

Alguns produtores, quando possível, conseguem vender seus produtos diretamente para os consumidores urbanos nas áreas próximas aos mercados e feiras. A venda efetivada diretamente é mais vantajosa aos produtores, mas ainda diminuta, sendo difícil de ocorrer durante todo o ano, pois o tempo necessário de permanência no local de comercialização, a distância e a disponibilidade de transportes, provoca custos adicionais com despesas de estadia e alimentação. Terminando o comerciante local como o comprador mais importante, seguido de barco de linha e de outros atravessadores.

Atualmente, esta situação vem mudando. Algumas Prefeituras Municipais intervêm e influenciam na comercialização dos produtos, ao participarem da organização da comercialização nos mercados e feiras de produtores. Como 
acontece nessa parceria com a ADS, na tentativa de incentivar e valorizar o produtor rural, na efetivação da sustentabilidade.

As unidades familiares de produção reconhecem as atividades como trabalho, enquanto o trabalho feminino, doméstico ou não (auxílio na lavoura, pesca, etc.), assim como o dos filhos é considerado “ajuda”, mesmo nas situações onde os trabalhos destes se dão através de tarefas equivalentes ou iguais as dos homens. As mulheres participam ativamente, em graus maiores ou menores, dependendo da comunidade, de todo o sistema de produção, desde as decisões sobre o que produzir, do plantio até a comercialização final.

\section{Da submissão ao surgimento do protagonismo feminino: a transformação do habitus na vida das mulheres camponesas}

A pesquisa realizada por Castro et al (2008), nas comunidades amazônicas nos revelou a grande participação das mulheres no espaço físico e social, de uma forma mais ou menos expressiva. Mesmo que nas sociedades seu trabalho ainda seja considerado como ajuda, parece que de forma inconsciente inicia-se uma quebra nas estruturas patriarcais herdadas das gerações anteriores, principalmente quando as mulheres passam a exercer atividades que antes não eram ou não podiam ser realizadas por elas. Este processo ocorre devido à busca de respostas às novas necessidades que surgem no cotidiano. A participação da mulher nos espaços produtivos como a agricultura familiar caminha junto com a percepção subjetiva que esta mulher tem de seu reconhecimento, no momento que passa a se ver como conhecedora e manipuladora do processo produtivo.

Em relação à região da Amazônia, a participação específica da mulher na agricultura familiar indica que ela desempenha um papel fundamental na sustentabilidade do processo de produção. Este tem sido o novo olhar para esta protagonista na cadeia produtiva das propriedades rurais, principalmente nos estudos acadêmicos. A sua participação na sustentabilidade é devido ao conhecimento e saber que esta tem em usar e manejar a terra. A mulher parece ter controle sobre a biodiversidade e a compreensão fundamentada nos domínios dos 
fenômenos naturais, tem conhecimento sobre a importância da conservação da natureza, além de ser ela própria o alicerce da produção agrícola e do bem-estar da família (Sousa, et.al., 2008).

O domínio do conhecimento que a mulher apresenta sobre o processo produtivo na agricultura familiar garante a sustentabilidade da propriedade, na esfera do trabalho com a terra, bem como influência na esfera das relações de gênero, para além do espaço específico do trabalho, na sustentabilidade como um todo da produção, visto que ela tem sua base de sustentação na família. $\mathrm{Na}$ perspectiva da sustentabilidade, a mulher tem o papel de defender a segurança alimentar da unidade familiar, através de sua atividade produtiva (CASTRO, et.al.,2008).

A mulher participa ativamente desde o preparo das mudas, a limpeza do terreno a ser cultivado, na colheita, no beneficiamento e na comercialização do produto final. Não existem dados estatísticos que deem conta de indicar a representatividade destas mulheres, visto que a participação e reconhecimento desta trabalhadora parte de sua subjetividade. De acordo com Castro et al (2008) o trabalho produzido pelas mulheres na agricultura familiar é subestimado pelas fontes estatísticas oficiais, sendo significativo nestes estudos o trabalho da mulher no espaço da casa. Os poucos estudos em relação à mulher na produção agrícola, indicam que apesar de 98\% participarem das atividades agrícolas, apenas 60\% participam da tomada de decisões na comunidade. As poucas mulheres que participam são as mais jovens pertencentes à atual geração.

De acordo com os estudos sobre Relações de Gênero, desenvolvidos por Míriam Nobre (1995), os movimentos das mulheres trabalhadoras rurais, nas suas mais diferentes vertentes, vêm construindo para a identidade política das agricultoras na busca de seu reconhecimento público. As mulheres trabalhadoras rurais iniciam um lento movimento de reivindicação de acesso à documentação profissional, pelo autorreconhecimento enquanto trabalhadoras e pela aceitação dos agentes públicos, da profissão de agricultora nos documentos, nos registros, serviços sociais e programas de inclusão social. 
Nas pesquisas atuais quem tem sido feitas com as mulheres camponesas feirantes, observa-se que elas começam a exercer atividades, que antes não eram comumente realizadas por elas, levadas pelas necessidades surgidas no cotidiano, ressignificando o seu trabalho e a valorização que lhe cabe. No entanto, apesar destas mulheres estarem adquirindo maior "emancipação política", muitas de suas ações ainda estão ligadas às ideologias repassadas pelos seus antecessores. Isso pode ser explicado pela noção de habitus descrito por Bourdieu: a teoria do habitus elaborada por Bourdieu permite entendermos os modos de vida, memória, identidade e ethos da mulher camponesa agricultora e, portanto, a permanência deste como um aprendizado do passado, como herança, porém dotada de criatividade que permite ao sujeito inovar, transformar sua prática social na busca da sua realização como agente criativo.

$\mathrm{Na}$ prática, vamos percebendo que o habitus não anula a história, já que como herança abre possibilidades para mudanças no todo social, podendo gerar sublevações. Basta pensarmos na luta pelo direito costumeiro que tem colocado os camponeses em uma situação de conflito, desde os Quilombos até nossos dias.

Neste movimento de permanência e mudança, fruto do habitus, a mulher camponesa vai se (re) criando. "Habitus é também adaptação, ele realiza sem cessar um ajustamento ao mundo que só excepcionalmente assume a forma de uma conversão radical” (1983b, p. 106).

O estudo sobre o habitus nos faz entender a (re)criação do camponês, porque ele ativa o agente, que ele contém em germe, a dinâmica, a possibilidade de no presente, acionado condicionamentos incorporados, de construir uma nova história - é o passado e o presente recriado, fazendo o futuro, trazendo a reinvenção (a transformação criadora) e adaptação (ou não) ao novo (mundo capitalista, cidade, etc.) 


\section{As feiras Camponesas do CIGS e do CASSAM}

A "Feira de Produtos Regionais do CIGS" acontece em Manaus, quinzenalmente aos sábados pela manhã, no bairro São Jorge, á partir das 6h, no pátio (estacionamento) do quartel do Centro de instrução de Guerra na Selva (CIGS).

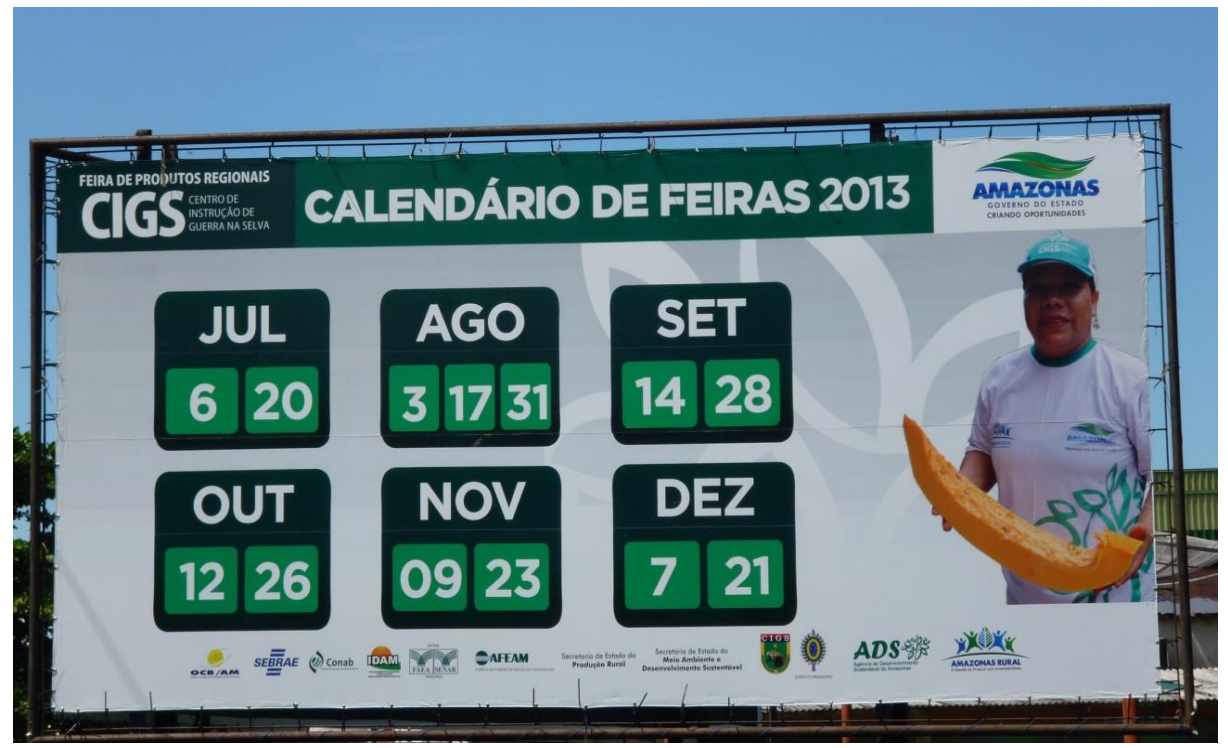

Figura 01 - Outdoor com o Calendário da Feira do CIGS 2013 - 2ºmestre Fonte - VARGAS (2013)

A princípio, a escolha do lugar e parceria com o Exército foi estratégica, pois o bairro é afastado do centro, não possuindo outras feiras nas proximidades, e também, o oferecimento da parceria com a disponibilidade do local partiu do Exército pensando em beneficiar as famílias militares do entorno com a compra de alimentos mais saudáveis e a preços acessíveis, além de propiciar oportunidades aos produtores locais. O que foi muito bem recebido pelos consumidores, abrangendo não só os familiares de militar, bem como os moradores dos bairros próximos.

A feira de mulheres do CASSAM, denominada "Feira da Economia Feminista e Solidária de Produtos Regionais", também acontece em Manaus, no quartel da Base Aérea de Manaus, no Clube de Suboficiais e Sargentos da 
Aeronáutica (CASSAM), quinzenalmente, nos sábados alternados com a feira do CIGS, iniciando às $6 \mathrm{~h}$. Segue o mesmo modelo de organização e parcerias que a feira do CIGS, com um diferencial que esta, após observações ao longo do tempo, em outras feiras, na participação, entusiasmo e melhorias na qualidade de vida das mulheres participantes, foi proposto a ADS a criação de um novo projeto de feira de produtos regionais específico para a mulher. Constata-se que muitas mulheres que são feirantes do CIGS, também vendem seus produtos na Feira do CASSAM. Isto pode ser evidenciado no relato da Agricultora-Feirante do município de Rio Preto da Eva.

É tudo ganha pão, a sobrevivência. Produzo de tudo, trabalbo com horta em estufa. Antes era no distrito, pedi demissão e comprei um sitio, trabalbo na horta, na casa e vendo nas duas feiras. Vendo bem, dá pra viver bem e gosto muito disso aqui. (S.C. M., 35 anos, agricultora, Rio Preto da Eva/AM.)

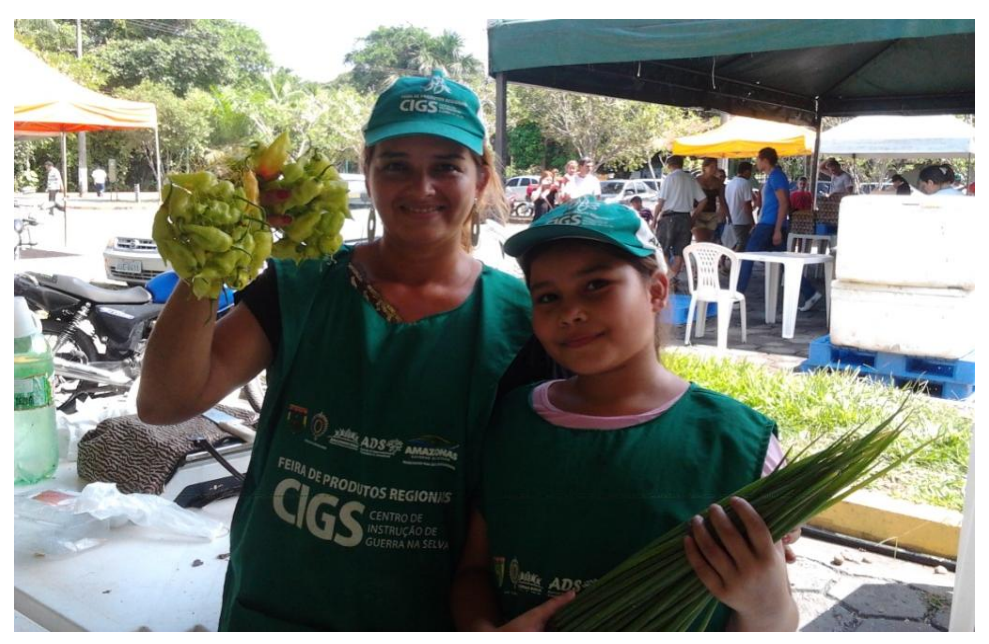

Figura 2 - Silvana e filha na feira Fonte: VARGAS (2013)

Para a realização da feira, a ADS cadastra os produtores que moram na Capital e no interior, que trabalham com produtos agrícolas, interessados em vender sua produção, por meio dos sindicatos e organizações formais e informais, providenciam as instalações, organizam o espaço físico. Prefeituras dos 
municípios de origem entram com o transporte dos produtos e dos feirantes para aqueles que não disponham de transporte próprio.

A dinâmica para os preparativos para a feira começam dias antes, pois o trabalho do campo exige cuidados diários e programados para se ter os produtos disponibilizados em tempo para que possam trazê-los à feira. Essa produção reforça o sentido do campesinato se produzir em pequenas áreas, o trabalho familiar e o sistema integrado e complexo de policultivos, combinando produção animal e vegetal.

A feira de produtos regionais como espaço de negócios é uma importante ferramenta para as mulheres camponesas comercializarem seus produtos diretamente ao consumidor, eliminando assim o atravessador. Planejar suas ações e participação na feira, mantendo sua produção e reprodução, escolhendo os produtos a serem comercializados, é também uma forma de organização em Movimentos, não só para obter renda, mas também de se opor ao modelo de comércio imposto e demonstrar (fortalecer) sua autonomia camponesa. Isso se torna bem visível nas entrevistas com algumas mulheres camponesas feirantes, onde estas demonstram sua satisfação em ter independência financeira e autoestima elevada pela realização e resultados da feira.

Essa feira pra mim significa muita coisa. Hoje en tenho prazer em trabalhar. Hoje eu sinto orgulho de trabalhar, tenho disposição em produzir e trazer produto de qualidade com preço bom. Conbecer pessoas diferentes. Foi uma mudança, uma melhoria, ajudou a pagar as contas, a sair de casa. Antes eu vivia muito triste, só em casa, trabalhando, trabalhando... aquele tédio... vendo a produção estragar... era muito triste. (R. L. F., 60a, agricultora familiar feirante, Comunidade José Lindozo, Rio P. da Eva / AM). 


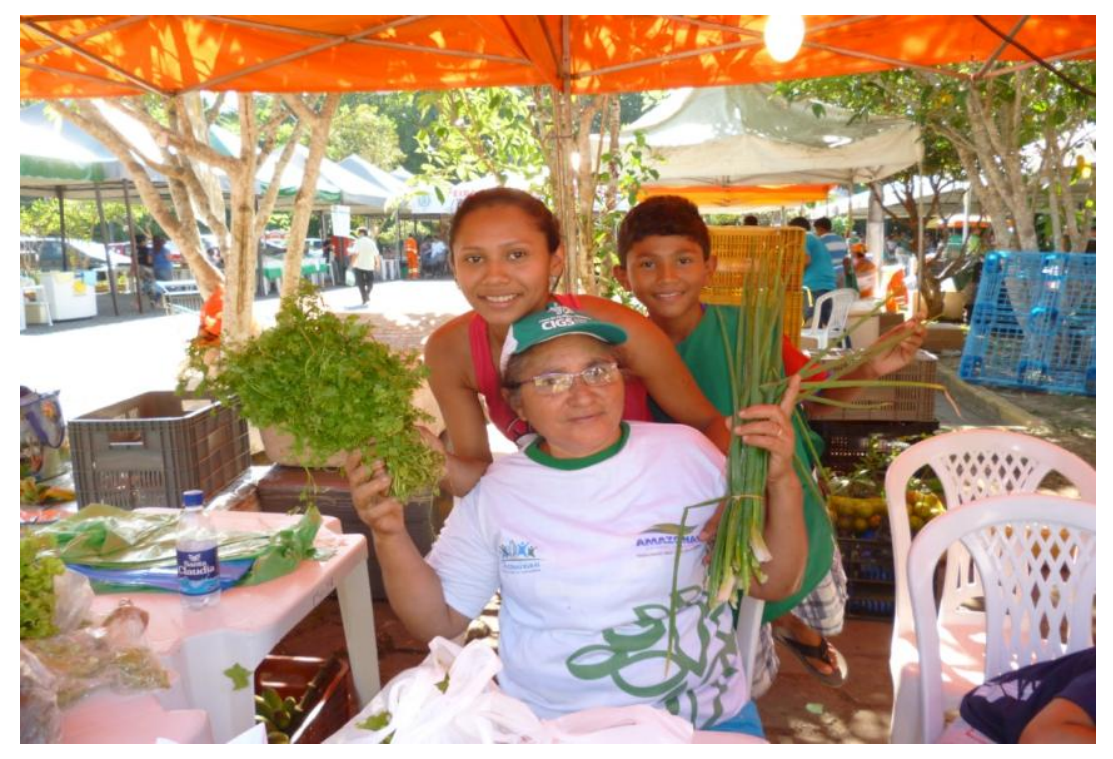

Figura 03 - D. Raimunda e netos. Feira do CIGS

Fonte: VARGAS (2013)

A feira é mais um beneficio. Aumenta a renda, Beneficio pra toda a familia. Porque vende direto (produz e vende), sem atravessador. As mulheres saem de casa. (R. A. S., 56 a.,agicultora, Comunidade São Cristóvão, Manacapuru/ AM).

As camponesas feirantes relatam em entrevistas, que o mais importante para elas é o "aumento da renda", a oportunidade de saírem de casa e conviverem com outras pessoas. Entendem por renda a simples transformação da mercadoria em dinheiro. Essa renda tem por objetivo principal a manutenção da família, em sua reprodução simples, como manter os filhos na escola e comprar produtos que não produzem, como os industrializados (café, açúcar, vestuários, querosene, etc.). Os gastos referentes às compras para a casa, roupas, calçados e materiais escolares são feitos com a "renda da feira". Mostram satisfação em poder participar do orçamento familiar, como seguem os depoimentos:

È pra casa, é pra família é pra casa, no início tá assim, as veis pode aumentá a renda e pode fazê uma outra coisa, mais é pra nóis aqui mesmo, é prá despesa, calçado, roupa pra eles (os filhos e marido), tá tudo aqui. Ta bão pra todo mundo. Tá o que precisa, ai a feira termina, a gente já vai no supermercado faz. uma comprinha, vem embora. Coisa pra escola, uma roupa, é tudo tirado da fera. (Maria l. set.13). 
Mudou tudo. Quase 100\%.com a feira, tenho tudo de bom em casa, eletrodomésticos, geladeira, freezer, televisão, fogão á gás, microondas...sei lá, tudo. Significa mais dinheiro, vendo bem na feira. Antes tinha o atravessador e não sobrava quase nada. Agora então, feira só de mulber..., a mulber trabalha mais, tem mais responsabilidade, determinada, de atitude. Muita luta, muito trabalho, mas é satisfatório. (S. F. O, 47a, agricultora, Iranduba / AM).

Com a venda direta ao consumidor, aprimora-se a estratégia utilizada pelas feirantes camponesas em valorizar seus produtos, pois agregam valor e ainda mantêm uma relação social com o centro urbano, obtendo uma melhor renda quando comparados a preços e dificuldades de comercialização anteriores a feira, além do rendimento financeiro, o que proporciona uma satisfação maior ainda, é de não ser explorada por atravessadores, e de outro lado poder programar as futuras produções, tendo em vista a continuidade da feira.

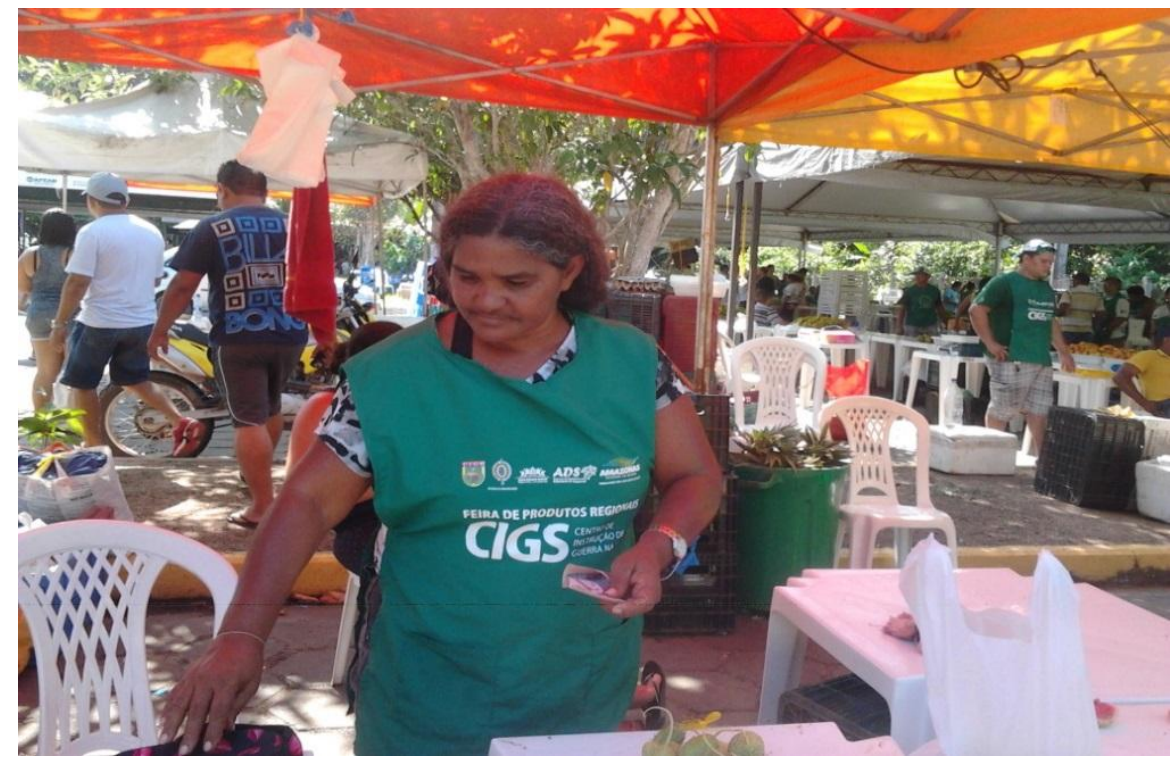

Figura 04 - R. A. S. conferindo a caixa do dinheiro.

Fonte: VARGAS (2013)

Observou-se nas feiras a satisfação dos consumidores em poder desfrutar daquele espaço, que além da compra de produtos de qualidade a um bom preço, tem o encontro, o convívio com amigos, conhecidos, outras pessoas do mesmo 
bairro, o saborear de um café com produtos regionais fazem da feira não só um lugar de comércio, mas também um lugar especial de reuniões e encontros.

\begin{abstract}
Percebe-se que a feira se encontra em um local seguro e bem organizado, onde temos a possibilidade de adquirir produtos de qualidade diretos do produtor. Uma oportunidade a mais e um incentivo ao produtor camponês. (J. N.V., 47a, consumidor, Feira do CIGS-Manaus / AM)
\end{abstract}

Nos depoimentos tanto das feirantes como dos consumidores vê-se a importância da feira para as mulheres camponesas e os moradores do bairro. E que a participação das mulheres em espaços públicos, reforça sua auto estima, segurança financeira, legitimando-se como trabalhadoras e donas de seu destino.

\title{
Considerações Finais
}

Característica marcante observada nas feiras estudadas (CASSAM e CIGS) é a presença da mulher, que assume papel de destaque, participação essa, indicadora de mudanças no papel da mulher na divisão do trabalho na unidade camponesa. Trata-se de uma nova perspectiva para as mulheres que ficavam ocupadas e submetidas aos trabalhos "menos importantes" na unidade familiar, para serem reconhecidas como fundamentais quanto à manutenção econômica da família.

A dimensão econômica avultou até desequilibrar a situação antiga das comunidades. A expansão do mercado capitalista não apenas força o camponês amazônico a multiplicar o esforço físico, daí surge a necessidade de reinventar a vida numa adaptação forçada.

As feiras criaram um espaço onde o papel da mulher sofreu alterações nas relações com a família e a sociedade, incorporando o trabalho com o objetivo de gerar renda e dignidade. Bem como contribuem sobremodo para a reprodução dos saberes-fazeres da cultura camponesa.

È possível perceber a consolidação de um novo modo de vida a partir das estruturas estruturadas através dos habitus do campo e da cidade que se 
amalgamaram de forma estruturante, resultando em um habitus híbrido no decorrer do processo dessa apropriação temporária do espaço das feiras a partir do exercício de novos papéis pela mulher feirante e dessa troca de culturas.

\section{Referências}

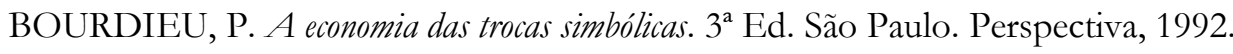
O desencantamento do mundo. São Paulo. Perspectiva. 1979.

CASTRO, Albejamere Pereira. Relações de Gênero e os Meios de Produção na Sustentabilidade das Comunidades Amazônicas. In: FRAXE, Therezinha de Jesus Pinto.

DIEGUES, A. C. O mito moderno da natureza intocada. São Paulo: Hucitec, 1996.

FRAXE, Therezinha de Jesus Pinto. Cultura cabocla-ribeirinha: mitos, lendas e transculturalidade. São Paulo: Annablume, 2004.

- Homens anfíbios: etnografia de um campesinato das águas. São Paulo:

Annablumme; Fortaleza: Secretaria de Desporto do Governo do Estado do Ceará, 2011.

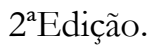

FRAXE, Therezinha J.P., MEDEIROS, Carlos M. (orgs.) Agroecologia, extensão rural e sustentabilidade na Amazônia. Manaus, fundação Universidade do Amazonas,2008.

FRAXE, T. J. P., PEREIRA, H. S., WITKOSKI, A. C., (orgs.) Comunidades Ribeirinhas amazônicas: memórias, ethos e identidade. Manaus. Reggo edições. 2011. Comunidades Ribeirinhas amazônicas: modos de vida e uso dos Recursos naturais. Manaus. Reggo edições. 2011..

NODA, Hiroshi. Agricultura familiar na Amazônia, segurança alimentar e agroecologia. www.emater.pa.gov.br/EmaterPortal/downloads/../agriFamAmz.pdf, 2009.

NODA, Sandra do Nascimento. Agricultura Familiar na Amazônia das Águas. Manaus: Editora Edua, 2007.

SOUSA, Lígia Costa; RODRIGUES, Priscila Freire; NODA, H. Participação da mulher na sustentabilidade da agricultura familiar na localidade de Jandira, Iranduba,Amazonas.

http://www.cnpat.embrapa.br/sbsp/anais/Trab_Format_PDF/130.pdf, 2008.

TEIXEIRA, P., et al (orgs). Produæir e viver na Amazônia Rural: estudo sociodemográfico de comunidades do médio Solimões. $2^{\mathrm{a}}$ Ed. Revisada. Manaus. Reggo edições. 2011..

WITKOSKI, Antonio Carlos. Terra, Florestas e Aguas de Trabalho. Manaus: Edua, 2007. 